\title{
A WEIGHTED DECISION MATRIX FOR OUTSOURCING LIBRARY SERVICES
}

\section{David Ball}

\begin{abstract}
David Ball is University Librarian at Bournemouth University and is a leading practitioner in the field of library purchasing consortia. He chairs Procurement for Libraries and the Libraries Group of the Southern Universities Purchasing Consortium, and has negotiated ground-breaking agreements with suppliers for services and materials. He also has experience in the private sector, as information manager for a major newspaper publisher.
\end{abstract}

\begin{abstract}
In 2000-2001 Bournemouth University Library carried out a study, funded by Resource: The Council for Museums, Archives and Libraries, to give an up-to-date view of the current experience of outsourcing and externalisation in libraries, museums and archives. Case studies of purchasers recognised as pioneers in the field, and of providers, were undertaken. As a result, a weighted decision matrix was developed as a tool for judging the suitability of library services for outsourcing. Illustrations of potential uses are given. (2747 words)
\end{abstract}




\section{INTRODUCTION}

In recent years there has been increasing interest in the United Kingdom, on the part of both central and local government, in the concept of outsourcing public sector services. This has been manifested in the libraries, museums and archives (but primarily libraries) domains by the encouragement of public/private sector partnerships, through such schemes as the Private Finance Initiative (PFI) and Public Private Partnerships (PPP). These approaches are opening up new possibilities for funding public service provision and the operation of the resulting asset by the private sector.

Interest in future outsourcing in libraries also derives from continuing budget restrictions, both revenue and capital, a focus on the customer and on results, benchmarking of services, provision of services between local authorities, public/private sector partnerships, and a purchaser/provider culture. Museums and archives have some experience of outsourcing and lessons learnt by these institutions may be transferable to the libraries domain.

The environment is substantially different now from 1995, when KPMG and Capital Planning Information Ltd. (CPI) reported to the Department of National Heritage on contracting out in public libraries (DNH study (1995)). This study concluded that, although externalisation was feasible, there was little evidence that the market existed to provide services as an alternative to the public sector. Westminster City Libraries have recognised the changing environment by approaching the market three times in attempts to outsource services.

In 2000-2001 Bournemouth University Library carried out a study, funded by Resource: The Council for Museums, Archives and Libraries (Resource Research Project, LIC/RE/108) to provide an up-to-date view of the current experience of outsourcing and externalisation in the library and information domain and its potential. Particular attention was paid to higher education, public and special libraries, and an assessment was made of the effects of the external economic, political and technical pressures on service providers leading to change. Information was also gathered from, and parallels drawn with, the other domains within Resource's remit, museums and archives, giving some indication of the context of, and scope for, cross-domain working.

The practical issues arising were documented through a series of case studies and focus groups, and discussed at a seminar attended by representatives from all three domains (Outsourcing: practice and opportunity in libraries, museums and archives: proceedings of a seminar held at Stamford, Lincolnshire on 22 March 2001 (2001)). The study also undertook an assessment of potential suppliers and agents in the market place: their capabilities, readiness, interests and future plans to meet increasing demands for outsourcing. The study concluded that, since the DNH study in 1995, there has been a significant trend towards outsourcing and externalisation, on the part of both customers and suppliers. A weighted decision matrix, recommended for judging the potential within an organisation for outsourcing, was therefore developed. The full study was published in late 2002 (Ball et al. (2002)). The present paper examines the weighted decision matrix. 


\section{BACKGROUND}

The purpose of the matrix or profile is to inform the decision on whether a service is a suitable candidate for outsourcing. It is designed as an aid to that process, not as a substitute for it. It is not designed to inform the decision on whether to outsource as a matter of strategy: that is an anterior political decision.

We have discovered one matrix designed specifically for libraries (Marcum 1998). In slightly modified form it is reproduced below:

\begin{tabular}{|l|l|l|l|l|}
\hline \multicolumn{3}{|l|}{ In-house } & \multicolumn{3}{c|}{ Outsource } \\
\hline Folklore & & & & (commodity) \\
\hline Mandated & & & & \\
\hline Background & & & & \\
\hline Priority & & & & \\
\hline Identity & (strategy) & & & \\
\hline & Alliance & Alignment & Reliance & Support \\
\hline
\end{tabular}

The vertical axis is a continuum for process, the horizontal for relationships.

On the vertical axis, 'folklore' processes are those for which there is no real justification except tradition: these, Marcum recommends, should simply be 'rooted out'. 'Mandated (legal, governmental)' and 'background' processes are candidates for outsourcing. 'Priority' processes, which have to do with 'effectiveness and major operations', and 'identity' process, which reflect or determine the organisation's identity, should be handled in house.

The horizontal axis characterises relationships with suppliers, partners, stakeholders etc., and also 'complexities of the interaction'. The headings are proposed categories for IT relationships. 'Relationships range from commodity items [in the top right corner] to strategic alliances' in the bottom left corner. The closer to the top right corner, the more suitable a candidate for outsourcing. While Marcum's matrix may be useful for characterising services or aspects of a service, particularly in the IT area, we believe a slightly different approach is necessary to take account of market and other conditions.

\section{FACTORS}

In the course of our research, and building on Marcum's example, we have identified nine cultural, economic and functional factors that merit consideration when assessing the suitability of a service for outsourcing. These factors are:

\section{a) Cultural}

- Peripheral to service identity - If a service or product is seen to define or be core to the overall service's relationship with its users, particular consideration should be given to the advisability of having it provided by a third party. Examples of core services might be: creation and maintenance of the content of a service's website; stock selection.

- Complies with corporate strategy(ies) - In the UK local government sector, Best Value implies that all services must be tested against any outsourced equivalent. The commercial sector will generally have a strategy of seeking low-cost flexible solutions. Increasingly the academic sector will follow the other two. However, 
the outsourced solution may conflict with other corporate strategies. For instance, in the local government sector, the authority may have the preservation or creation of local jobs as a priority; outsourcing a service where there are no local providers runs counter to this priority.

- Corporate policy - Secondary services, such as cleaning, security, may be outsourced as a matter of corporate policy.

\section{b) Economic}

- High revenue cost - One main reason for outsourcing is that specialist suppliers should be able to offer economies of scale or innovative delivery of service. Given a properly constructed contract, such economies will be shared with the customer. The higher the revenue cost, therefore, the greater the potential financial benefit of outsourcing.

- High capital cost - Public sector organisations in particular often face severe constraints on capital investment, whether in terms of the availability of capital or the length of time over which capital has to show a return. Outsourcing to the private sector is one means of easing such constraints.

- Market/suppliers exist - It seems an obvious truth that, if there are no prospective suppliers, there is little possibility of outsourcing a service. One may further question the wisdom of outsourcing a service to a monopoly or near-monopoly supplier. The economic rationale for outsourcing a service is to benefit from the effects of competition in depressing prices and increasing efficiency and service. Where there is no competition prices rise at the whim of the monopolist, and there is no motivation for efficiency. Having outsourced a service, it may be very difficult to bring it back in-house. Organisations may also wish to consider creating suppliers through regional or other collaboration.

\section{c) Functional}

- Difficult to deliver service - There are many reasons why a service may be difficult to deliver. There may be sudden unpredictable peaks of activity or demand. Maintaining in-house staffing levels to cope with the peaks may be impossible; the specialist contractor will have much higher capacity. Opening service points outside core hours may be impractical or very expensive using directly employed staff, but achievable using agencies. There may be no in-house expertise for specialist work, such as design; there may be a lack of specialist knowledge, for instance relating to health and safety.

- Poor or declining performance - "If it ain't broke don't fix it" is a useful precept. If, on the other hand, there is dissatisfaction with a service (catering is a frequent example) an innovative approach by an external supplier working to tight performance measures may bring both cost-savings and increased user satisfaction. One danger must, however, be highlighted here, which reportedly has been evident in the field of IT outsourcing. Managers must first understand a problem before turning to outsourcing as a solution. Outsourcing without such understanding will tend to bring more headaches rather than a cure.

- Easy to specify - One view often advanced is that routine tasks are easiest to specify and bring benefits in terms of cost-savings and enhanced performance when outsourced. The procurement profession would hold that it is possible to construct a specification for the vast majority of services or products. Difficulties tend to 
arise from a lack of clarity on the part of those writing the specification. While we support this contention, the lack of clarity is itself an impediment to outsourcing: if one cannot describe one's requirements for the marketplace, suppliers will not be in a position to meet them. This factor may in fact indicate an internal organisational immaturity rather than a difficulty in specifying and procuring the service.

However the immaturity itself would be an impediment to success in outsourcing.

It will be apparent from the above that some factors contradict others. For instance, a high revenue-cost activity might imply both a high level of in-house expertise and a non-peripheral service. Obviously individual institutions will balance the different factors as they see fit.

We suggest the following ways in which the factors may be applied.

\section{SIMPLE MATRIX}

The first is a straightforward matrix. The factors are simply listed. The more ticks in the right-hand column(s), the more likely the service is as a candidate for outsourcing.

\begin{tabular}{|l|l|l|l|l|}
\hline \multicolumn{1}{|c|}{ Factor } & No & \multicolumn{2}{c|}{ Yes } \\
\hline Cultural & & & & \\
\hline Peripheral to service identity & & & & \\
\hline Complies with corporate strategy(ies) & & & & \\
\hline Corporate policy & & \multicolumn{4}{|l|}{} \\
\hline Economic & & & & \\
\hline High revenue cost & & & & \\
\hline High capital cost & & & & \\
\hline Market/suppliers exist & & & & \\
\hline Functional & & & & \\
\hline Difficult to deliver service & & & & \\
\hline Poor or declining performance & & & & \\
\hline Easy to specify service & & &
\end{tabular}

Again it is worth noting that this is not a prescription: we do not recommend the automatic outsourcing of services with say five out of nine ticks in the right-hand column. Rather, a profile of ticks to the right suggests a service as a suitable candidate for an outsourcing exercise.

For instance, analysis of an in-house catering service might produce the following profile: 


\begin{tabular}{|l|l|l|l|l|}
\hline \multicolumn{1}{|c|}{ Factor } & No & \multicolumn{3}{c|}{ Yes } \\
\hline Cultural & & & $\sqrt{ }$ & \\
\hline Peripheral to service identity & & & $\sqrt{ }$ & \\
\hline Complies with corporate strategy(ies) & & $\sqrt{ }$ & & \\
\hline Corporate policy & \multicolumn{4}{|c|}{} \\
\hline Economic & $\sqrt{ }$ & & & \\
\hline High revenue cost & $\sqrt{ }$ & & & \\
\hline High capital cost & & & & $\sqrt{ }$ \\
\hline Market/suppliers exist & & & & \\
\hline Functional & & & & $\sqrt{ }$ \\
\hline Difficult to deliver service & & & & $\sqrt{ }$ \\
\hline Poor or declining performance & & & & $\sqrt{ }$ \\
\hline Easy to specify service & & & & \\
\hline
\end{tabular}

The institution would then form its view as to the importance of the factors in the left-hand half of the grid. Despite the low cost-implications in this hypothetical example, the potential of the practicality of an outsourcing solution (the suppliers exist; the service is easy to specify) and of turning around a service perceived as poor, may make this a prime candidate.

Institutions will of course wish to expand or otherwise modify the matrix. When considering whole-service outsourcing for instance, one might wish to expand the corporate strategies element.

A university might therefore assess compliance of outsourcing its library service with its Strategies for Information, Learning and Teaching, Regional Involvement, and Research, as well as with the strategies of the institution as a whole and of individual faculties. It may well be that integration of the library service and its staff with the academic process and with quality assurance is central to the Learning and Teaching and Research Strategies, while pursuit or consideration of outsourcing is central to the overall institutional and Information Strategies. This could yield the following profile.

\begin{tabular}{|l|l|l|l|c|}
\hline \multicolumn{1}{|c|}{ Factor } & No & \multicolumn{1}{l|}{ Yes } \\
\hline Cultural & \multicolumn{2}{|l|}{$\sqrt{ }$} & & \\
\hline Peripheral to service identity & & & & $\sqrt{ }$ \\
\hline Complies with Information Strategy & & & & \\
\hline Complies with L/T Strategy & $\sqrt{ }$ & & & \\
\hline Complies with Research Strategy & $\sqrt{ }$ & & & $\sqrt{ }$ \\
\hline Corporate policy & & & & \\
\hline Economic & & & & $\sqrt{ }$ \\
\hline High revenue cost & & $\sqrt{ }$ & & \\
\hline High capital cost & & $\sqrt{ }$ & & \\
\hline Market/suppliers exist & & & & \\
\hline Functional & & & & $\sqrt{ }$ \\
\hline Difficult to deliver service & & & $\sqrt{ }$ & \\
\hline Poor or declining performance & & $\sqrt{ }$ & & \\
\hline Easy to specify service & &
\end{tabular}


The university would then form its view. The left-hand half of the grid shows a slight preponderance; a contra-indication may be the importance to the institution of its overall strategy or policy and the Information Strategy. Again these are matters for judgement, political as well as economic. The purpose of the matrix is to inform that judgement, not to substitute for it.

\section{WEIGHTED MATRIX}

Institutions may wish to refine the matrix by assigning weightings to factors. In the last example, for instance, it was suggested that the university might assign a higher weighting to its overall strategy and its Information Strategy. Weighting may be achieved by grouping factors into bands and assigning numerical values to the degrees of compliance.

To take a simple example, an institution facing severe financial restrictions might apply the following weighted model:

\begin{tabular}{|c|c|c|c|c|c|}
\hline Weight & Factor & No & & & Yes \\
\hline & & 1 & 2 & 3 & 4 \\
\hline 3 & High capital cost & & & & \\
\hline 3 & Market/suppliers exist & & & & \\
\hline 3 & High recurrent cost & & & & \\
\hline 2 & Complies with cornorate strateov(ies) & & & & \\
\hline & & & & & \\
\hline & & & & & \\
\hline 2 & Easy to specify service & & & & \\
\hline 1 & Perinheral to service identity & & & & \\
\hline 1 & Corporate policy & & & & \\
\hline 1 & Difficult to deliver service & & & & \\
\hline & & & & Total & \\
\hline
\end{tabular}

The score is arrived at by multiplying the value of the degree of compliance by the weighting. Thus the cash-strapped library authority might assess the provision and maintenance of IT equipment as follows: 


\begin{tabular}{|c|l|c|c|c|c|}
\hline Weight & \multicolumn{1}{|c|}{ Factor } & No & $\mathbf{1}$ & $\mathbf{3}$ & $\mathbf{4}$ \\
\hline & & & & & 12 \\
\hline 3 & High capital cost & & & 9 & \\
\hline 3 & Market/suppliers exist & & & & 12 \\
\hline 3 & High recurrent cost & & & & \\
\hline 2 & Complies with corporate strategy(ies) & 2 & & & \\
\hline 2 & Poor or declining performance & & & 6 & \\
\hline 2 & Easy to specify service & & 4 & & \\
\hline & & & & & \\
\hline 1 & Peripheral to service identity & & & 3 & \\
\hline 1 & Corporate policy & 1 & & & \\
\hline 1 & Difficult to deliver service & & 2 & & \\
\hline & & & Total & $\mathbf{5 1}$ \\
\hline
\end{tabular}

The same authority might assess another candidate, supplier stock selection, thus:

\begin{tabular}{|c|l|c|c|c|c|}
\hline Weight & \multicolumn{1}{|c|}{ Factor } & No & $\mathbf{2}$ & $\mathbf{3}$ & $\mathbf{4}$ \\
\hline & & $\mathbf{1}$ & $\mathbf{2}$ & \\
\hline 3 & High capital cost & & 6 & & \\
\hline 3 & Market/suppliers exist & & & & 12 \\
\hline 3 & High recurrent cost & & & & \\
\hline & & 2 & & & \\
\hline 2 & Complies with corporate strategy(ies) & 2 & & 6 & \\
\hline 2 & Poor or declining performance & & & 6 & \\
\hline 2 & Easy to specify service & & & & \\
\hline & & & & & \\
\hline 1 & Peripheral to service identity & 1 & & 3 & \\
\hline 1 & Corporate policy & & & & 4 \\
\hline 1 & Difficult to deliver service & & & Total & $\mathbf{4 3}$ \\
\hline
\end{tabular}

The profiles are quite similar if one takes account only of distribution across the two halves of the matrix. Both have 4 entries in the left two columns and 5 in the right two columns; if all factors are given a weighting of 1, IT scores 24 and suppler selection 22. However the weighted score shows IT equipment as the more appropriate candidate to meet the authority's requirements, with a score of 51 against 43 for supplier selection.

This application of the matrix is therefore of use in comparing a range of services as candidates for outsourcing against corporately defined criteria.

\section{CONCLUSION}

We believe the matrix is a useful tool for assessing services as candidates for outsourcing. It is not a substitute for professional or political judgement. Nor is it a substitute for a professionally conducted procurement process. Once the decision, informed by use of the matrix, to approach the market is made, normal procurement practice must be adopted. It is at this stage that factors such as cost and quality of service will be assessed. The level of risk of the potential contract can also only be 
assessed at this stage. Only then will the status of the contractors and the resilience of the marketplace become clear.

\section{REFERENCES}

Ball, David et al. (2002) A study of outsourcing and externalisation by libraries, with additional reference to the museums and archives domains. Bournemouth: Bournemouth University (Resource research project, LIC/RE/108. BUOPOLIS, 5)

DNH study: contracting-out in public libraries (1995). London: KPMG and Capital Planning Information Ltd.

Marcum, James W. (1998). Outsourcing in Libraries: Tactic, Strategy, or "Meta-Strategy"? Library Administration \& Management, 12(1), 15-25

Outsourcing: practice and opportunity in libraries, museums and archives: proceedings of a seminar held at Stamford, Lincolnshire on 22 March 2001 (2001), edited by Stuart Brewer. Loughborough: Capital Planning Information Ltd. 